\title{
Ogu - A Form of Death from the Perspetive of Healing
}

\author{
Dong Kwang, Ra1)
}

\begin{abstract}
A dream is a clue to the understanding of human unconsciousness. Unconsciousness is an important concept in psychoanalytic counseling therapy. The reason is that psychoanalysis is based on unconsciousness. Ogu - A Form of Death is a work in which the life of a human being facing death appears. This study analyzed the old mother's dream, discovered anxiety about death lurking in the dream, and determined how the anxiety was relieved. The psychology of anxiety, which may differ in degree, is a syndrome found in every human being. A ritual plays the role of removing the fear of an unknown world and maintaining peace. One of the Korean traditional shamanism rituals is gut. Contrary to a memorial service among noble families, gut has been widespread among common folks, and treated their joys and sorrows. Such a function is found in the round of Ogu gut. Ogu - A Form of Death has a process of solving the unsolved problem specifically through a ritual in the space between a dream and realities. It is characterized by healing through the psychology of anxiety before the existence of death is overcome.
\end{abstract}

Key words: Anxiety, Death, Dream, Tears, Psychoanalysis

\section{Introduction}

Healing is one of the important key words regarding pastoral duties or counseling. In principle, healing is associated with disease. A patient whose body shows a symptom is given priority in being healed. However, those suffering mental distress are the target of healing. Moreover, healing is essential to those who experience a life crisis or who are afraid of the existence of death. Therefore, healing is the work of attending to souls as well as to physical and mental problems. While the resources for healing are basically worship and Christian texts, including the Bible, their scope may widen according to the target. When healing is given to foreigners, literature within their culture and way of thinking is taken into account; literary works containing Korean traditional ceremonies can be used to heal Koreans. Therefore, this study is going to view Lee Yun-taek's Ogu - A Form of Death from the perspective of healing.

Received(September 26, 2018), Review Result(1st: October 15, 2018, 2nd: November 15, 2018), Accepted(December 10, 2018)

1) (Professor) 48434 Dept. Theology, Kyungsung University, Namgu, Busan, Korea

email: radkang@ks.ac.kr 
In the 1990s, when popular appeal became a cultural issue, dramatic art based on public participation made human life fuller. A popularized comedy, Ogu - A Form of Death is a work in which emphasis is placed on the public realities[1]. It is also a type of post-modern experimental theater that deconstructs the Western structure of time and space into a Korean traditional concept of time and space. This is because everydayness, specific ethnicity, and healthy humor of secular life inherent in Korean shamanism are boldly expressed through modern techniques[2].

Shin Hyeon-suk makes an approach to the space of the stage from the semiotic perspective. For her, space is not fixed, but has lots of meanings. She divides space into this and that worlds, and a surreal one. In particular, it is notable that she uses an imaginative mind to see surreal space, which is the essence of the work[3].

Kim Yun-jeong pays attention to the fact that Ogu - A Form of Death, which started from dramatic art, was transformed into the medium of film. However, she indicates the weakness of the film, that it cannot interact with the audience. Ultimately, she tends to place emphasis on drama rather than on cinema[4].

Yun Il-su focuses on the fact that Ogu has been revised continuously since 1989. He reveals the meaning from the perspective of folklore. What attracts his attention is the appearance of angels of death. In early times, there was no angel of death. The fact that one was made to appear later is associated with the combination of life and death issues[5].

Seo Deok-min compares the plots of the drama and the film. He indicates that the film integrates segmented plots and rearranges narratives linearly. It seems that the drama can be made into a film because it uses a functional aspect of "gut."[6]

Hwang Hun-seong revises the Brechtian concept of Gestus to identify deconstructive dramaturgy. The concept of Gestus implies the ideology of social conflicts and historical awakening. However, he seems to emphasize that Ogu sets forth as a premise the restoration of the Korean people's sensitivity through enlightenment of epistemological culture[7].

As mentioned above, many different studies have been conducted on Ogu - A Form of Death. However, no specific or special approach has been made in practice from the perspective of healing.

\section{Dream Analysis}

The mime that starts with the scene of the old mother taking a nap in midsummer results from the writer's intention to make contact with the afterlife. When she turns on a radio, the 
frequency is connected with communication in the other world. The mother enters the stage of sleep, listening to the song of white hair played on the radio. The world unrolling before her eyes during the nap is that of paramita, which is a 'scene in a dream.' The writer explains the dream by connecting it to the back of daily life.
A dream is the back of daily life;
as the late poet Kim Su-young said that death exists
behind a folding screen, the back of our daily life
gets turned over in a moment like this.
First, daily time and space is deconstructed, the form of life consolidated by animateness would be decomposed, despite such things as reason, morality, honor, and dignity of alive human beings[8].

Daily life is time and space that makes reason work. It is a life unfolded in a social structure governed by ethics. However, its other side cannot be controlled by reason or ethics. Contrary to the surface, the other side is the 'back of daily life', which involves the deconstruction of daily life and the decomposition of formal life. The deconstruction of daily life is found in dreams. As an expression of suppressed subconsciousness in daily life, a dream is a clue to the understanding of human unconsciousness.

Unconsciousness is an important concept in psychoanalytic counseling therapy[9]. The reason is that psychoanalysis is based on unconsciousness. Unconsciousness, which is differentiated from consciousness, is a part of mentality deep in the abyss. It is impossible to know unconsciousness directly because it never surfaces. Unconsciousness is divided into the cases that can be made conscious and those to which no approach can be made. The former is preconscious and the latter is unconscious[10].

Freud contended that unconsciousness is suppressed in the area of consciousness[11]. Conscious suppression can make a certain idea disappear. However, it does not mean that the idea is dispelled by suppression. Some day it can appear suddenly in spite of oneself. In other words, suppressed ideas are placed at a point from where they can enter the area of consciousness at any time[12].

Ideas disappearing at midday can often appear at midnight when one sleeps. Sometimes they can appear when one takes a nap. In other words, unconsciousness works freely when it is out 
of suppression[13]. A dream is unconscious activity. In a dream, people do not express only their own ideas. This is because their wish to be fulfilled in illusionary experiences can appear[14]. A wish that appears in a dream may be disguised[15]. Human pleasure is mostly accompanied by wish fulfillment. However, a wish may go through the process of censorship in special relationships of a dreamer. It is found in an unsatisfactory state characterized by a mix of the one who pursues a wish and the one who rejects it[16].

The first exploration to which priority needs to be given in dream analysis is condensation. Condensation is a function of a dream to integrate people that appear or events that develop. Even a single dream can contain a diversity of latent things. In other words, condensation is a state in which only a smaller, revelatory dream exists, despite a lot of latent dream contents[17].

The second exploration is displacement. Displacement is a phenomenon in which two different things are linked and replaced. Dream thinking can differ from a dream. In a dream, however, a certain element in charge of dream thinking may be replaced. Here, a possible work of a dream is disguise.

The third exploration is representation. Representation is to present an idea in an image. Freud discovered a symbol during the process of studying representation and emphasized its meanings.

The revelatory shape which a latent content takes is a symbol. An empty bowl is the representation of a womb and a stick is that of a penis[18]. In other words, a symbol of a dream is a primitive expression of language[19].

There are diverse materials of a dream, ranging from the experiences that involve infantile regression in childhood to recent trivial matters. In addition, physiological desires may become materials of a dream. In particular, they include an impression of the day before the dream[20]. The value of the impression may depend on the contents lurking on the bottom. An analysis needs to be made to identify the shape of a dream, which is fairly disguised. Dream analysis is accompanied by dream interpretation. Clients tell their dreams and the therapist interprets and heals them.

The old mother's unconsciousness latent in her inner world gets freed through her dream. In her dream, spirits appear. This is evidence of the influence of Korean traditional shamanism. The spirits hovering in her mind include 'Mondalbi Spirit,' 'commanding spirit generals with Cheongryongdo,' who come out of a rice chest, and 'Maid Spirits,' who spring out of shamanistic stories of spirits in her childhood and appear in her dream[21]. However, it does not mean that their appearances make her personal unconsciousness expressed. Spirit 
appearance is a phenomenon at the early stage and unconsciousness is revealed at the climax of the dream.

In the climactic scene of the dream, a paper boat appears. The old mother finds her late husband, Lee Seok-i, land from the boat. Her husband had been conscripted and died. His appearance has been her wish for fifty years. It has been met in her dream. However, the joy of the reunion is momentary.

The old mother starts to recognize herself, watching two commanding spirit generals smile.

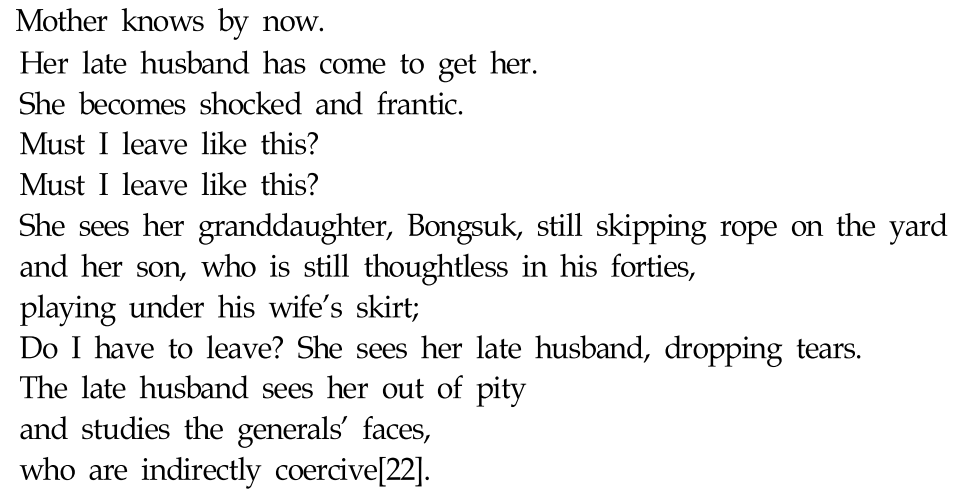

For the old mother, her late husband's appearance not only means that her wish is met, but also notifies her imminent death. The notification makes her so confused that she gets 'shocked and frantic.' Moreover, the commanding spirit generals are threatening beings because their smiling faces are changed all of sudden. However, it is not regarded as their changes, but as an expression of the old mother's psychology of anxiety in confusion. That is, she has arrived at the climax of anxiety. This psychology of anxiety, which may differ in degree, is a syndrome found in every human being. When there is no preparation for death, the sudden notice of death can arouse the climax of anxiety.

\section{Anxiety Relief through Ritual}

A ritual plays the role of removing the fear of an unknown world and maintaining peace. One of the Korean traditional shamanism rituals is gut. Contrary to a memorial service among noble families, gut has been widespread among common folks, and treated their joys and sorrows. Such a function is found in the round of Ogu gut. 
Seokchul: (Toward audience) The old woman Ghang Bok-rye has lost her husband in the Greater East Asia War when she was still young...

Mother: Yes

Seokchul: She has been desperate

for her children's learning by herself,

selling vegetables, boiled rice, rice cake, cloth, an so on...

Mother: Not boiled rice

(Pause)

Seokchul: You once mentioned it, didn't you?

Mother: You created it, When did I mention it?

Let's correct it completely

because this seems to be the last gut.

Seokchul: Let's do that

Selling (pause) no boiled rice, but rice cake

saving money little by little to buy a house

along with some land

making lots of money.

Now she only has to go to the paradise

all of her sufferings and savings are in vain[23].

It is Seokchul who leads the ritual. He prepares for a round of gut and leads it, mentioning joys and sorrows in the old mother's life. The old mother has been bereaved of her husband, who was conscripted to the Greater East Asia War. She has not avoided any hard work but made efforts to rear her children. The old mother saying 'not boiled rice' and Seokchul confirming her saying it arouse laughter. Therefore, a ritual contains pleasure as well as reverence. This is somewhat characterized by a kind of dual aesthetics of drama[24]. However, Seokchul's acceptance of the old mother's history is regarded as consideration for the client.

Along with the sequence of the female shaman's dances with songs, the leader of the ritual, holding a gourd, continues to console the client. At the same time, he induces her to enter the world of paradise. In this process, the client's decision to visit her ancestors weakens.

The feelings of the old mother, who has to bid permanent farewell to her son and granddaughter, are expressed in the act of 'yelling' because of perplexity. While she remains calm at the early stage, she repeats 'I cannot go' with agitation. Finally, she wails. The cry represents every human being's hope to reject death as well as the old mother's hope to avoid bidding farewell to her child. Aid has a meaning of counseling therapy due to the understanding of and sympathy with the old mother. The act of making the client shed tears 
and burst out crying is regarded as a kind of teardrop therapy centered on the client. This is because the attempt to let the client talk freely and shed tears is therapeutic.

\section{Conclusion}

Ogu - A Form of Death is a work in which the life of a human being facing death appears. This study analyzed the old mother's dream, discovered anxiety about death lurking in the dream, and determined how the anxiety was relieved. This has great significance for human beings not experiencing death. For Christians, anxiety is relieved by a church service based on deathbed and funeral procedures. Church service is based on the ceremony loyal to a program. However, contents are more important than form. In the process of accepting death, priority is given to sufficient counseling about the problem of anxiety. Even a Christian, who has the shadow of traditional collective unconsciousness, needs a process of healing to solve the problem because he has a Korean mind. Ogu - A Form of Death has a process of solving the unsolved problem specifically through a ritual in the space between a dream and realities. It is characterized by healing through the psychology of anxiety before the existence of death is overcome. However, it focuses on a play for the living and neglects the fear of uncertainty about the soul after death. This seems to be the lack of a belief system, which involves resurrection, leaving the issue of afterlife unsettled.

\section{References}

[1] S. Y. Jeong, A Study on Lee Yun-taek's 'Popular Theater' - Its Strategies and Meanings in the Field of Theater in the 1990s, Doctoral Thesis, Hanyang University, (2004), pp.1-176.

[2] M. J. Park, Deconstruction and Routinization of the Temporal and Spatial Structure in Modern Dramas, Research on Dramatic Art of Korea, (1995), Vol.5, pp.337-376.

[3] H. S. Shin, Culture and Semiotic Theory and Analysis: A Semiotic Analysis of Dramatic Space - Focusing on Ogu - A Form of Death, Semiotic Research, (1995), Vol.1, pp.332-358.

[4] Y. J. Kim, A Review of Filming the Drama Ogu - A Form of Death, Research on Modern Culture of Korea, (2006), Vol.19, pp.449-476.

[5] I. S. Yun, Changes in Performance of Ogu Directed by Lee Yun-taek, Linguistics and Literature, (2007), Vol.98, pp.405-434.

[6] D. M. Seo, The Issues of Acceptance of Traditional Performances by Dramas and Media Transition - 
Focusing on Making the Drama Ogu - A Form of Death into a Film, Yongbong Collection of Treatises in Humanities, (2011), Vol.38, pp.173-193.

[7] H. S. Hwang, Dance of Death: Gestus Approach to Lee Yun-taek's Ogu, Comparative Literature, (2010), Vol.18, No.1, pp.37-62.

[8] Y. T. Lee, Ogu- A Form of Death, Seoul: Gong-gan, 1994, edited by Y. H. Seo and N. S. Kim; Lee Yun-taek's Complete Works of Performance Scripts, Drama and Human Beings, (2006), Vol.6, p.158.

[9] James Strachey, The Complete Psychological Works of Sigmund Freud, 1940-1986, London; Hogarth, (2014).

[10] James Strachey, The Complete Psychological Works of Sigmund Freud, 1940-1986, London; Hogarth, (2014), Vol.19, p.16.

[11] James Strachey, The Complete Psychological Works of Sigmund Freud, 1940-1986, London; Hogarth, (2014), Vol.19, p.15.

[12] James Strachey, The Complete Psychological Works of Sigmund Freud, 1940-1986, London; Hogarth, (2014), Vol.14, p.149.

[13] James Strachey, The Complete Psychological Works of Sigmund Freud, 1940-1986, London; Hogarth, (2014), Vol.5, p.608.

[14] James Strachey, The Complete Psychological Works of Sigmund Freud, 1940-1986, London; Hogarth, (2014), Vol.15, p.129.

[15] James Strachey, The Complete Psychological Works of Sigmund Freud, 1940-1986, London; Hogarth, (2014), Vol.4, p.160.

[16] James Strachey, The Complete Psychological Works of Sigmund Freud, 1940-1986, London; Hogarth, (2014), Vol.15, p.216.

[17] James Strachey, The Complete Psychological Works of Sigmund Freud, 1940-1986, London; Hogarth, (2014), Vol.15, p.171.

[18] James Strachey, The Complete Psychological Works of Sigmund Freud, 1940-1986, London; Hogarth, (2014), Vol.5, pp.353-360.

[19] James Strachey, The Complete Psychological Works of Sigmund Freud, 1940-1986, London; Hogarth, (2014), Vol.15, pp.166-168.

[20] James Strachey, The Complete Psychological Works of Sigmund Freud, 1940-1986, London; Hogarth, (2014), Vol.4, p.180.

[21] Y. T. Lee, Ogu- A Form of Death, Seoul: Gong-gan, (2006), p.159.

[22] Y. T. Lee, Ogu- A Form of Death, Seoul: Gong-gan, (2006), p.160.

[23] Y. T. Lee, Ogu- A Form of Death, Seoul: Gong-gan, (2006), pp.165-166.

[24] S. M. Lee, Dual Aesthetics of Drama with a Ritual and Play - Focusing Lee Yun-taek's Dramas, Korea Culture Research, (1999), Vol.2, pp.129-144. 